about the same course as that for pure water, except that the maximum of density was reached, not at $4^{\circ}$, as in the case of purc water, but under $3^{\circ}$, as is the case with salt substances.

RECENT observations by 14 . Ebermayer demonstrate (I) that the air in a large forest is in summer nearly twice as rich in carbonic acid as íree open air ; (2) that forest ground in summer contains much less $\mathrm{CO}_{2}$ than unwooded ground (the $\mathrm{CO}_{2}$ formed by slow decomposition of humus in the close forest seems mostly to pass into the air, and is probably utilised by the leaves for assimilation); (3) that, with rise of temperature, the increase of $\mathrm{CO}_{2}$ in arable ground is very much greater than in forest ground; and $(4)$ that the spread and motion $\mathrm{CO}_{2}$ in the ground seems to take place very slowly, for in two places quite near together the amount of $\mathrm{CO}_{2}$ may be very different. Among other bearings of these facts, the ground covering of a forest can have no important influence on the amount of $\mathrm{CO}_{2}$ and lime in spring water, and unwooded ground may have a greater action in this respect. Again, animals living underground, e.g. foxes, naturally prefer the ground air of the forest, with its little $\mathrm{CO}_{\vec{z}}$, to to the ground air of the open field, which has much more.

THE influence of concentration of liquids on their electromo. tive force has lately been investigated by M. Moser (Monatsb. der Berline'r Acad. der Wiss.) who connected two glasses of differently concentrated solutions of the same salt by a siphon, and completed the circuit by wires with electrodes, which were always of the same metal. In all such cases a current arises, passing in the liquid from the dilute to the more concentrated solution. M. Moser used zinc sulphate, nitrate, chloride, and acetate, copper sulphate and vitrate, iron chloride, silver acetate and nitrate, and other salts. The highest electromotive force was $\frac{1}{5}$ Daniell, and was got with very dilute and concentrated zinc chloride solution. The various effects are arranged in tension series. By the currents referred to, metal is dissolvect in the dilute solution, separated out in the concentrated one. The equivalent of the work done by the current, M. Moser considers, is the work of attraction force between the salt and the water. The current is to be regarded as a reaction current against passage of the ions, as the polarisation currext is the resction current against the decomposition current.

Tile subject of acoustic repulsion contintes to be studied by M. Dvorak (Wiit. Ann., No. 3). Among other things he constructs an acoustic reaction wheel and an acoustic torsion balance. The former consists of four light paper or glass resonators placed tangentially at the four ends of two thin cross-bars of wood, pivoted at their intersecting point by means of a glass cap. The mouths of the resonators are all in the same relative position. The wheel is placed before the open end of a tuningfork resonator, and enters into rotation when the fork is sounded. In another case the sound from the large resonator is transmitted through a conical tube beyond whose thin end is a wheel with square pieces at the end of the cross-arms. In the acoustic torsion balance a wooden bar furnished with a resonator is hung by a wire (as in Coulomb's balance) within a case, which has on the resonator side an opening for admission of sound. By repulsion of the resonator the strength of tones of the same number of vibrations may be compared.

LECTURING at the Sorbonne lately on atmospheric clectricity, M. Mascart sought to reproduce the phenoniena of thunderstorms. The dull explosions of thunder and the fulgurations in the heart of clouds preceding fulminant discharges, as also the latter, were imitated by menns of a powerful Holtz machine, charging batteries, and condensers suitably arranged. The singular movements of thunder-clouds, which, obeying electric attractions and repulsions, are often observed to move in the atmospheric occan in counter-currents, were illustrated with the aid of a balloon of hydrogen gas, to which was susfended a piece of metallic wire. The weight of the wire was such that the small aerostat, rendered slightly heavier than the displaced air, would descend; but when it was electrificd, it rose again, as if freed from its burden. M. Mascart did not attempt an explanation of this curious phenomenon, which has not been repeated since the time of van Marum.

IN a recently-published report by M. Kellner to the Naturforscher Versammlung at Munich, he describes experiments made along with some others on an eleven-year old Wallachian horse of 434 kilo. weight, with regard to the relation of work dine and decomposition of albumen. In five successive periods of thirteen to fourteen days the animal was fed with $5 \mathrm{k}$, meadow hay, $5 \mathrm{k}$. oats, and $\mathrm{I} \cdot 5 \mathrm{k}$. chopped wheat straw, and did work to the extent of 500,000 , I, 000,000, I, 500,000, $1,000,000$, and 500,000 kilogrammetres in the five periods re spectively. In periods $I$. and V. the work done was the same, in II. and IV. doubled, and in III. tripled; in II. and III. the course was doubled and tripled, and in IV. the weight doubled. Of the dry substance of the fodder were digested in period I. $56^{\circ} 53$ per cent., II. $56^{\circ} 45$ per cent., III. $56^{\circ} 49$ per cent., IV. $54^{\circ}$ OI per cent., V. $53^{\circ} \circ 7$ per cent. The horse's weight varied as follows :-I. $534^{\circ}$ I, II. $5^{2} 9^{\circ}$ I, III. $522^{\circ} 3$, IV. $508 \cdot 8$, V. $5 \mathrm{rS}$ kilo. The excretion of nitrogen was on an average of the last six to nine days of each experimental series, I. $98.8 \mathrm{x}$., II. $109^{\circ} 16$, III. II $9^{\circ} 82$, IV. 107.53 , V. 101 88 . These numbers show strikingly, in opposition to Voit's and Petten kofer's results, that with increase of work done, is associnted a not inconsiderable increase of decomposition of albumen.

THE additions to the Zoological Society's Gardens during the past week include an Indian Leopard (Fclis pardus) from India, presented by Major Tubbs; a Ked Deer (Cervus elapinus); a Common Fox (Canis vulpes), European, presented by Mr. Carroll W. Ansdell; two Spotted Ichneumons (Herpestes auro. punctatus) from Nepal, presented by Mr. J. McIntosh; a Suri. cate (Suricata zenik) from South Africa, presented by Mr. Percy Howard; an Azara's Fox (Canis azarce) from Brazil, presented by Dr. A. Stradling; a Stanley Crane (Tetrapteryx paradisea) from South Africa, presented by Capt. A. F. Lendy; a Lead. beater's Cockatno (Cacalua leadbeateri) from Australia, presented by Mr. W. Ruston; a Collared Fruit Bat (Cynonycteris collaris), four Common Foxes (Canis vulpes), born in the Gardens.

\section{THE DETERIORATION OF OIL PAINTINGS} II.

IF we compare the pictures of the Italian and Dutch schools of the fifteenth, sixteenth, and seventeenth centuries, with those of the French and English schools of the last hundred years, we are struck by the great difference in the nature of their diseases. We may divide those diseases into constitutional ones-that is to say, such as are based on the method and the material used for painting, and into those produced by external influences.

The Dutch pictures of the fifteenth, sixteenth, and seventeenth centuries, and the Italian pictures of the fifteenth and sixteenth centuries, seem to me perfectly free from constitutional diseases. $\mathrm{It}$ is only in the seventeenth century that the Italian pictures show a special constitutional alteration, caused by the practice of the Bologna school.

The pictires of the last bundred years of the French school, of a part of the English school, and some painters of other achools, have been attacked by a constitutional disease perfectly defined and characteristic of this period.

Among external influences injurious to oil painting, we have to consider dampness, heat, bad air, dust, smoke, mechanical injuries, and lasf, not least, the destructive or "altering" hand of the picture-restorer.

Pettenkofer's scientific researches first clearly defined the influence of humidity on oil paintings, showing that it produced a discontinuity of the molecules of the vehicle and the resinous substances. As glass, when pulverised and thereby mixed with air, loses its transparency, and water, when mixed with oil,

'Paper read at the Royal Institution, Friday, March $x$, by R. Liebreich, M.D., M.R.C.S., M.R.I. Continued from p. 195 . 
hecomes of a milliy aspect, so the oily and resinous substances contained in paintings will become dim as soon as air penetrates between their particles. The picture thus assumes a greyish, dim apperrance, and the pigments seem to bave been fading. That this is not really the case has been proved by the influence of a process invented by Pettenkofer, which he calls regeneration. In a flat box the picture is exposed to air impregnated with alcohol. Of this latter the resinous elements of the picture absorb a certain quantity, swell and fill up the interstices between the separated particles so as to reunite them into an optically homogeneous transparent substance.

The alcohol does not affect in the same way the hardened oil. If the interstices between its particles are not filled up by the swellino resin, it becomes necessary to introduce a new substance into the picture, and this is called nourishing a picture.

Pettetikofer has the great merit of having clearly proved that the nourishing of a picture with oils, as the custom was formerly, and still is to some degree, is a very objectionable proceeding, as it has the effect of darkening the colours for ever. He recommends, instead of oil, balsam of copaiva, which has become since an invaluable means for preserving and restoring oil paintings, and will be more and more extensively used.

I have frequently applied Pettenkofer's method, and with very beneficial effect; but whenever I mentioned it to professional picture-restorers, here as well as on the Continent, I always found them to reject it, either $i$ priori, or after experiments incorrectly made.

In Munich, it seems, the pictures of all periods and of all schools liave had to strffer under Iocal influences and through the change, in the humidity of the air. This accsunts for Pettenhofer having principally described this, so to say, endemical disease. In other galleries this affection does not appear so frequently, and Pettenkofer's method, therefore, will not find everywhere the salie extensive application as at Munich. I think, however, that with some modifications it may be employed arrinis some other alterations. I have, for instance, found it efficacious with painting which had been injured by exposure to great heat. I shall sliow you a small picture which had been han ying for a long time so near a gas flame that it was almost completely scaling off, and so entirely faded that it scarcely hoked like an oil painting at all. In that state it was exposed to alcoholised air, then nourished with balsam, and its back sirghtly varnished; and the scales starting from the canvas were retixed is py preme. And now it appears fresh in colvur, firm in substance, and perfectly smooth on its surface. The old, eracted varnish, melted logether by the alcohol, looks as if fresh laid on.

Humidity sometimes favours the development of fungus. The round, black, small spots which pass through the canvas and the painting of these two pictures are produced by the same little plant which Prof. Tyndall sliowed you when he spoke on the highly interesting subject of spontaneous seneration.

Oil and water, so injurious to oil paintings, enter both into the material used for lining. Anxious to exclinde these sources of danger, and to simplify the whole process, I have endeavoured to replace it by a new method which I shall submit to you this evening.

How paintings may be disfigured by restorers you see in this picture, which was renovated with oil colours according to the practice only abandoned about thirty years ago, when it was advantageously replaced by the use of varnish colours.

The amount of external injury oil paintings sometimes endure and stand is perfectly amazing. Pictures in the course of centuries, churing the destructive fury of wars and revolutions, may have been torn out of their frames, rescued from below the ruins of burned monasteries, may subsequently have passed from one bric-a-brac shop to another, where they have been piled up, to be pulled about at each new inspection, and literally trodden under foot, whereby they have finally been reduced to a state of colourless, greyish, or black rags. Still such pictures may not unfrequently be awakened, as it were, to new life, to their original brilliancy of colour, if, with all necessary care, their injured limbs are put together again, their wounds are healed, and fresh nourishment, air, and thorough cleansing, are administere 1 to their lacerated bodies.

A sound constitution is, of course, a necessary condition for obtaining any such result, without it we can only obtain a partial cure. We see this with reference to the Bolognal school of the seventeenth century. The pictures which you see here are instance; of this. From the state of rags to which they were reduced they have passed, by appropriate treatment, into the state of firm, even, well-conditioned, and clean pictures. The constitutional alteration characteristic of their time and school, however, could not be cured. You will, therefore, perceive that the contrast is too great between light and shade, that the half tones are too weak and that the glazings spread on clark ground, which certainly existed formerly, have been destroyed by the growing of bolus and umber of the priming. That this is not the fault of the method of restoration is clearly proved by the state in which you will find all the pictures of this school, even those best preserved in the best galleries of all countries.

The constitutional diseases of pictures belonging to the French and to the English school of the last hundred years are of still more serious nature, and much more difficult to cure. Many of them, though they were mever exposed to any injury whatever, nor are likely ever to be so in our present state of civilisation, cannot be guarded from premature decay in spite of all possible care with which they are kept.

The principal symptoms of their bad constitution are :-

I. Darkening of the opaque bright colours.

2. Fading of the transparent brilliant colours.

3. Darkening, and above all, cracking of the transparent dark colours.

The best opportunity to study these several appearances is given us in the Museum of the Louvre, which contains a great number of such pictures in the section occupied by the French school. I have paid particular attention to the cracks in these pictures, as I find that in stape, in size, in position, ns well as in relation to the various colours, they differ distinctly from the cracks in older pictures and in those of other schools. This, of course, is of importance, not only for the explanation of the reasons which produced them, but as a symptom which, in a given case, might determine the diagnosis, whether a picture be an original or only a copy. The special characteristics of these cracks are the following :-

They are all but exclasively found in the thickiy laid on transparent dark colours, and they are the decper and the more gaping in proportion to the thickness of the layer of the colour and the extent of the dark surface. The chief cracks rum parallel to the outlines of surfaces painted with bright opaque colours, such, for instance, as are nsed for the flesh tints, and which are more or less thickly laid on. But there is generally a slight distance between the bright colours and the cracks.

Lateral branches of these cracks pass into the white, lut they do not gape, provided the white colour: had been laid on directly upon the priming, and not upon a layer of dark transparent and not sufficiently dried colour.

This examination of the craclis of pictures has sometimes afforded me a peculiar insight into the practice used for the picture. In the well-known picture, for instance, by Guericault, of "The Wreck of the Mledusa," in the Gallery of the Louvre, the cracks follow exactly the outlines of the bright flesh-tints. The arm of one of the dead bodies hanging in the water is so covered by planks and water that nothing of the forearm is to be seen. It is, however, very easy to prove that originally that arm was painted in all its length, for the cracks do not only follow the outline of the visible upper arm, but also the no longer visible forearm, and all the five fingers. This proves that the fore part of the arm and the hand were originally painted in flesh-tints before they were covered over by the planks, and the water painted afterwards. In Ingres' portrait of Cherubini, the face of the latter is beautifully preserved, while that of the Muse, as well as her drapery, is covered with cracks. In the depth of the cracks of the white drapery an intense blue tint is to be seen. Mr. Henry Lehmann, of Paris, the favourite pupil of Ingres, who knows the history of this picture as an eye-witness, and whom I consulted about this very striking appearance, gave me the following information :Ingres painted the head of Cherubini in Paris, and then took it with him to Rome. There it was pieced into a new canvas and lined. Then the Muse was painted, and before the colours were perfectly dry, another model was chosen, and a new Muse painted over the old one. The colour of the clrapery was likewise altered, and this explains the cracks in the white colour, and explains also why the blue appears in the depth of the cracks of the drapery.

Among the English artists of the last hundred years, some have painted with the same material and by the same process as their French contemporaries, and consequently with the same unfortunate results. Others avoided these by using the same 
material with more precautions. Others, again, and among them Sir Joshua Reynolds, have in their different works followed various practices, and consequently had varied results. Thus, some of Sir Joshua's pictures have kept perfectly sound. Others are cracked in the characteristic way just mentioned. Others, "sain, are cracked in an absolutely irregular way. We can earily form an idea of it if we read in his "Diary Notes," for in'tance, the way in which he painted the portrait of Miss Ki:kman, which he began with whiting and gum tragacanth, then covered it successively with wax, then white of eggs, and then varnished it.

The study of the alterations already fully developed in pictures painted within the last hundred years only, and their comparison $\checkmark i$ ith the works of the old masters, would suggest the following rites for the process of painting :-

I. The oil should in all colours be reduced to a minimum, and under no form should more of it than absolutely necessary be int:oduced into a picture.

2. All transparent colours which dry very slowly should be ground, not with oil at all, but with a resinous vehicle.

3. No colour should be put on any part of a picture which is not yet perfectly dry; and, above all, never a quick-drying colour upon a slow-drying one, which is not yet perfectly dry.

4. White and other quick-drying opaque colours may be put on thickly. On the contrary, transparent and slow-drying colours should always be put on in thin layers.

If the effect of a thick layer of these latter is required, it $m \mathrm{t}$ be produced by laying one thin layer over another, taking care to have one completely dry before the next is laid on. If transparent colours are mixed with sufficient quantity of whitelead, they may be treated like opaque ones.

Ve come now to the last layer of the picture, to that one which is spread over its surface in order to equalise optical ircunlarities, and to protect it at the same time from the air. I viean the varnish.

The varnith nay crack or gee dim; then it should be treated with l'ettenkofer's method; but it may become dark yellow, bi swn and dirty, and so hide the picture that it becomes necesmary to tale it off and to replace it by a thin layer of new varnish. It is here that picture-restorers, or we may say pictureclcuners, display their beneficial skill, and also their very de iructive activity.

If a picture is throughout painted in oil, if its substance has rem ined sound and even, and varnished with an easily solublo n: : Lich or dammar varnish, then there will be neither difficulty $n y$ (linger in removing the varnish. This can, in such a cace, be done either by a dry process, that is, by rubbing the surface with the tips of the fingers, and thus reducing the varnish by degrees to a fne dust, or by dissolving the varnish by application of liquids, which, when brought only for a short time into contact with the oil p:inting, will not endanger it. We have, however, seen that the w juls of the old masters are not painted with oil colours like those u $c$ s by modern painter;, but, on the contrary, that certain pignents, and especially the transparent colours used for glazing, we:ce ground only with resinous substances. These latter have, in the course of time, been so thoroughly united with the leyc: of varnish spread over the surface of the picture, that the ce no longer exists any decided limit between the picture and the varnish. It is in such pictures that a great amount of experience, and knowledge of the process used for the picture, 2. well as precaution, are required in order to take away from the virnish as much only as is indispensable, and without interfe:ins with the picture itself. Numberless works of art have been irreparably injured by restorers, who, in their eagerness to remove dirt and varnish, attacked the painting itself. They the: destroyed just that last finishing touch of the painting, without which it is no longer a masterpiece.

The difficulty and danger are much greater in cleaning those pictures which have not been varnished with the ordinary easily dissolved mastich or dammar varnish, but have been painted over with oil, oil-varnish, or oleo-resinous varnish. It seems incredible that these substances should ever be used for such purposes; it is, however, a fact that there are still people who fancy that it will contribute to the good preservation of their pictures to brush from time to time a little of those liquids over their surface. They recognise too late that the varnish becomes more and more dark, of a brownish colour, and opaque. If such varnish has afterwards to be removed, then we meet with the great difficulty, that this can be done only with substances which would just as easily dissolve the whole picture as the hardened layers spread over it.

This shows what can be the value of those universal remedies which from time to time appear, and are praised for the innocuous way in which pictures by their means may be cleaned.

There is at this moment a great discussion going on in Italy about Luporini's method. Luporini is a painter and picturerestorer in Pisa, who believes himself to have invented a new means of cleaning pictures without any danger. Some months ago, in Florence, I examined a large number of pictures cleaned by him. Those of the Gallery of St. Donato, belonging to Prince Demidoff, mostly Flemish and Dutch landscapes, are cleaned very well and without any injury to the painting. On the contrary, the St. John, by Andrea del Sarto, one of the finest pictures of the Palazzo Pitti, I found very much altered by the restoration of Luporini. I had studied that picture very closely the year before, and should now sooner believe it to be a modern copy than the cleaned original. It has lost all softness of outline and the characteristic expression of the face. The change in the flesh tints can scarcely be explained otherwise but by an entire removal of the glazing.

I think it is taking a heavy responsibility to allow a new experiment to be tried upon stch an invaluable work of art. Even private persone, who are fortunate enough to be in possesssion of such treasures, ought to feel responsible for the good preservation of masterpieces, which are, it is true, their material property, but which intellectually belong to the whole civiliced world of the present and of the future.

\section{UNIVERSITY AND EDUCATIONAL INTELLIGENCE}

Cambridge.--Messrs. Mackren, Robbs, and Hichens, have been appointed to Scholarships in Natural Science at Cronville and Caius Collegre.


the degree of Doctor of Science in the Department of Mental Science, was conferred on Jacob Gould Schtrman, I3.A.; in the Department of Mathenatics on Alexander Macfarlane, M.A., B.Sc.; in the Department of Chemistry on William Inglis Clark, B.Sc. The degree of Bachelor of Science was conferred on William Thomson in the Department of the Mathematical Sciences; on John Adrian Blaikie and James Johnstone Loblyie in the Department of the Physical Experinental Sciences; on William A. Haswell in the l)epartment of the Natural Science:; on James Alfred Ewing and John Gray in the Department of Engineering; and on John Brown, M.D., John Berry Haycraft, M.B., C.M., and John Trehame, M..B., C.M., in the Department of Public Health. The Hope Prize Scholarship in (hemistry was awarded to Mr. Lewis Johnstone, and the Falconer Memoris Fellowship for the encouragement of the study of Palrentclogy and Geolory, of the annual value of Ioo'., tenable for two years, and conditionally for four years, was awarded to R. A. Lundie, M.A., B.Sc.

BALTIMORE.-We recently referred to the system of fellowships at the Johns Hopkins University, Baltimore. From a statement on the subject which bas come to hand, we learn that twenty fellowships, each yielding 500 dols. a year, are annually open in the University. They are awarded by the trustees on the nomination of the Faculty, as nearly on the first of June as may be found practicable. Candidates are invited from any part of the country. The object of this foundation is to give to a few scholars of promise the opportunity to prosecute further studies, under favourable circumstances, and likewise to open a carzer for those who propose to follow scientific and literary callings. The University expects to be benefited by the presence and infuence of the Fellows, and by their occasional services; from among the number it hopes to secure from time to time some of its teachers. Three of the twenty fellowships are allotted this year to each of the five departments, Greek, mathematics, chemistry, physics, and biology; and the remaining five will be allotted either in these departments or in others, at the discretion of the Faculty. Appointments are made by a careful consideration of all the evidence submitted to the Faculty. Every candidate in presenting his name is expected to address a letter to the president indicating the course of his previous reading and study, and his general purposes with reference to future work. It is desirable for him to present in printing or manuscript an essay or thesis which may have been written either 